IdeAs

Idées d'Amériques

$17 \mid 2021$

Villes et culture dans les Amériques

\title{
Despojo y derechos territoriales: dinámicas de la violencia en contra de los pueblos indígenas en Colombia
}

July Calderón Segura

\section{OpenEdition}

Journals

Edición electrónica

URL: https://journals.openedition.org/ideas/10021

DOI: 10.4000/ideas.10021

ISSN: 1950-5701

Editor

Institut des Amériques

\section{Referencia electrónica}

July Calderón Segura, «Despojo y derechos territoriales: dinámicas de la violencia en contra de los pueblos indígenas en Colombia», IdeAs [En línea], 17 | 2021, Publicado el 01 marzo 2021, consultado el 04 junio 2021. URL: http://journals.openedition.org/ideas/10021; DOI: https://doi.org/10.4000/ideas. 10021

Este documento fue generado automáticamente el 4 junio 2021.

\section{(c) (i) (2)}

IdeAs - Idées d'Amériques est mis à disposition selon les termes de la licence Creative Commons Attribution - Pas d'Utilisation Commerciale - Pas de Modification 4.0 International. 


\title{
Despojo y derechos territoriales: dinámicas de la violencia en contra de los pueblos indígenas en Colombia
}

\author{
July Calderón Segura
}

1 La concentración de la propiedad de la tierra ha sido una de las causas del conflicto y posiciona a Colombia como el país más desigual de América Latina al tener uno de los índices de Gini más altos: 0.897 en 2014 (OXFAM, 2017). Las inconsistencias sobre la propiedad de la tierra reflejan la inseguridad jurídica territorial afectando los procesos de reforma agraria e incentivando los conflictos por la tierra, los cuales favorecen el mantenimiento de las condiciones de despojo y la violencia sociopolítica en los territorios rurales.

2 El último informe de Global Witness "Defender el Mañana" publicado en 2020 refiere que Colombia es el país más peligroso del mundo para la defensa del territorio y del medioambiente. En efecto, ocupa el primer lugar en asesinatos de líderes y lideresas, alcanzando el $30 \%$ de los asesinatos a nivel mundial y con una tasa de crecimiento del $150 \%$ con relación al año 2018. El informe señala con preocupación que cerca de la mitad de los asesinatos en el país fueron en contra de miembros de los pueblos indígenas quienes representan el $4 \%$ de la población nacional (Global Witness, 2020).

3 El incumplimiento de la implementación del Acuerdo de Paz ha significado una reconfiguración del conflicto y una amenaza para la vida del liderazgo social. Según la organización INDEPAZ (Indepaz, 2020), se han registrado 681 asesinatos en contra de líderes y lideresas sociales de diferentes procesos organizativos; cerca del 30\% de los asesinatos se registraron en contra de los pueblos indígenas y el 50\% ocurrieron en campesinos.

4 El presente artículo abordará tres grandes temas: el primero está relacionado con el estado actual del derecho al territorio desde los procesos de formalización de los pueblos indígenas. El segundo presenta un estado general de la violencia en contra de 
los pueblos indígenas desde la adopción del Acuerdo de Paz y la tercera parte aborda estas violencias de manera general en el marco de la pandemia por la COVID-19.

\section{Un indígena sin tierra es como un fogón sin leña?: despojos e intereses económicos en los territorios indígenas.}

Los pueblos indígenas en Colombia han venido enfrentando la pérdida de su territorio como consecuencia de los diferentes procesos de colonización, evangelización y violencia. Los territorios indígenas han tenido una importancia trascendental pues en ellos se adelantaron proyectos económicos llevados por actores externos a los pueblos. Ha llevado a la movilización del derecho y de la institucionalidad para el reconocimiento de ciertas formas de propiedad a los pueblos indígenas en aras de avanzar en procesos de asimilación. En efecto, tal fue el sentido inicial que dio origen a la ley 89 de 1890.

6 La creación de diferentes campos de poder y confrontación por parte del Estado han llevado a que los pueblos indígenas adelanten diferentes acciones desde las recuperaciones de tierras históricas como la solicitud de la formalización de territorios indígenas a través de la vía legal. Si bien la titulación de un número importante de resguardos se ha llevado a cabo desde la segunda mitad del siglo XX, es importante señalar que la falta de una continuidad jurídica que respaldara estos procesos generó un vaivén en la cantidad de titulaciones que se llevaron a cabo.

7 Actualmente, en Colombia avanza la constitución de resguardos de pequeño tamaño en hectáreas a diferencia de los años anteriores. Durante la década de los años 70, los cinco resguardos constituidos alcanzaban una extensión de 79.280 hectáreas, con un promedio de 15.856 hectáreas por resguardo.

8 En la década de los años 80 , se registró el periodo con mayor cantidad de hectáreas formalizadas - aproximadamente 23.931.626 - comprendidas entre 197 resguardos, con un promedio de 121.480 hectáreas (ODTPI, 2020). Posteriormente, en los años 90 y con el cambio constitucional, se constituyeron 296 resguardos con 4.079 .932 hectáreas, con un promedio de 13.783 hectáreas (ODTPI, 2020). En cuanto a las hectáreas formalizadas durante el siglo XXI, se registran cerca de 966.694 hectáreas en 275 resguardos, con un promedio por resguardo de 3.515 hectáreas, siendo el promedio territorial formalizado más bajo desde el inicio del proceso.

9 A corte de 31 de julio de 2019, han sido reconocidos 774 resguardos con un área aproximada de 33.257.400 hectáreas. Aún existen cerca de 889 solicitudes de formalización vigentes y se desconoce el número total de hectáreas en solicitud. El 20\% de las solicitudes de formalización han sido incluidas en el Plan de Atención y tan sólo el $4 \%$ hacen parte del Plan de Acción 2020 de la Agencia Nacional de Tierras, quedando el $80 \%$ en rezago.

10 Estas inconsistencias en el acceso a la tierra vulnera los derechos de los pueblos desde una pluralidad de perspectivas: la desaceleración en la formalización y la reducción en las hectáreas de los resguardos desconoce la realidad y necesidad de tierra de las comunidades indígenas como consecuencia del crecimiento poblacional; la falta de acceso a tierra afecta notoriamente los procesos de soberanía alimentaria y desarrollo de una economía propia porque en su mayoría los resguardos son zonas de reserva 
forestal o sitios sagrados, en los cuales está prohibida su explotación; se empiezan a registrar desplazamientos comunitarios ante la contaminación o destrucción de las fuentes hídricas; $y$, las comunidades han venido siendo despojadas, confinadas o desplazadas de sus territorios como consecuencia del conflicto armado.

La falta de seguridad jurídica y el estancamiento en los procesos de formalización de los territorios indígenas son la consecuencia de intereses específicos de ciertos sectores de la economía para adelantar proyectos de construcción de infraestructura, proyectos agroindustriales o de explotación de recursos naturales, porque algunos de estos proyectos se traslapan con las solicitudes de formalización como ocurre con el caso del sector minero (Ver Mapa 1). En departamentos como la Guajira, Chocó, Antioquia, Putumayo, Nariño y Cauca se registran traslapes de gran proporción; además, en los departamentos de Nariño y Cauca se presenta el $59 \%$ de los asesinatos en contra de pueblos indígenas.

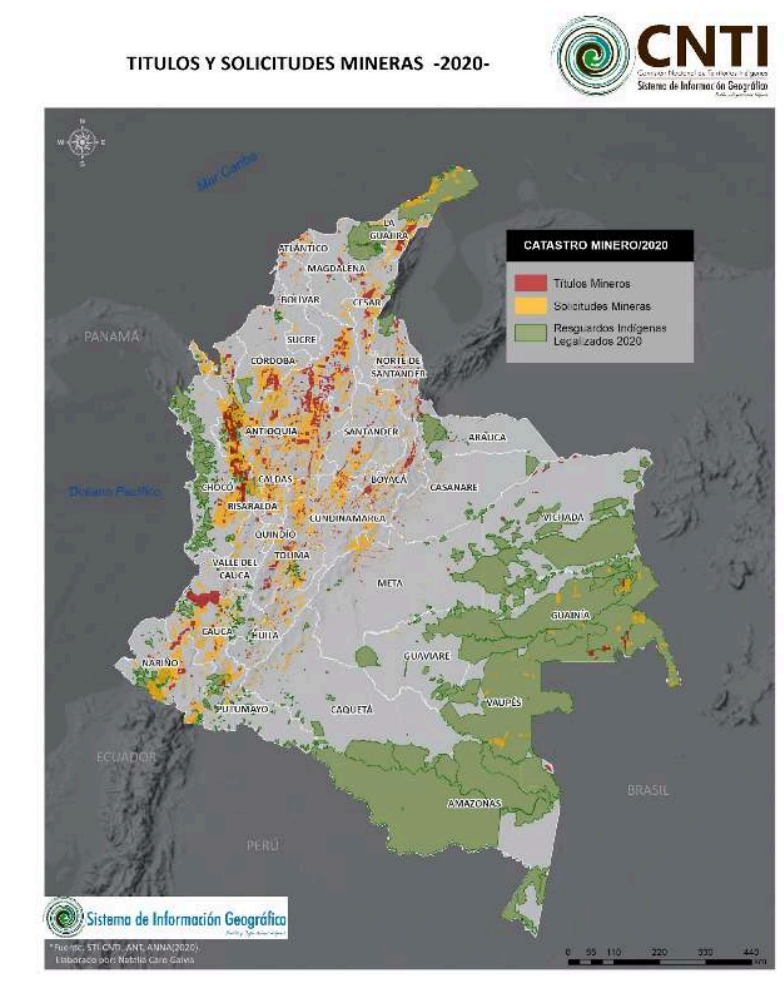

Traslape solicitudes de formalización de territorios indígenas con minería

\section{Violencia contra indígenas desde la implementación del acuerdo de paz}

El despojo de tierras ha sido una de las principales causas de la guerra en el país y los procesos de recuperación del territorio explican el comportamiento de la violencia registrada en contra de los de los pueblos indígenas en Colombia. El Observatorio de Derechos Territoriales de los Pueblos Indígenas registra, desde la adopción del capítulo étnico en el acuerdo de paz el 25 de agosto de 2016 a corte de 31 de diciembre de 2019, 198 asesinatos en contra de los pueblos indígenas (Ver Mapa 2). 


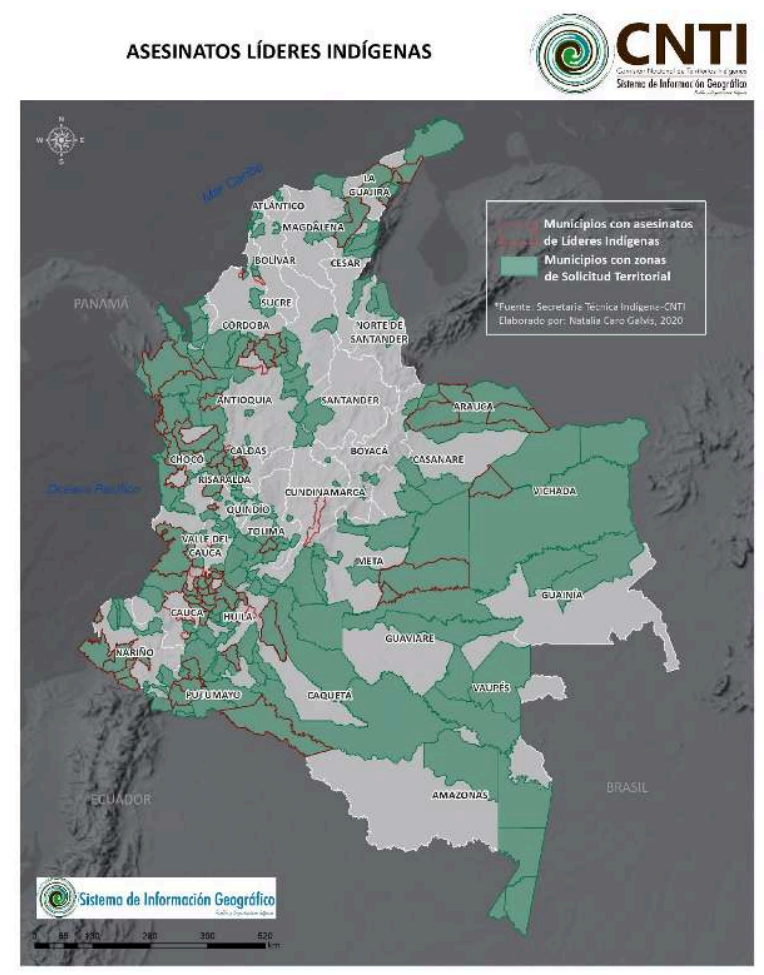

Asesinatos de líderes y lideresas indígenas en Colombia con traslape de solicitudes de formalización de territorios indígenas

La proporción de indígenas entre el conjunto de líderes asesinados tiene un aumento progresivo: en 2017 se registró el 19\%, en 2018 el 34\% y durante el 2019 el 42\% de los asesinatos. Los pueblos indígenas más afectados han sido el pueblo Nasa con el $43 \%$, el pueblo Awá con el 16\% y la nación Emberá con el 16\%. El 36\% de los asesinatos corresponden a líderes indígenas, el $33 \%$ son comuneros indígenas, seguidos por miembros de la Guardia Indígena ${ }^{2}$ con un $15 \%$, el $8 \%$ son autoridades ancestrales, lideresas indígenas el $5 \%$ y el $2 \%$ son familiares de autoridades indígenas. El $68 \%$ de los asesinatos se han registrado en el suroccidente del país en departamentos como Cauca (42\%), Nariño (17\%) y Valle del Cauca (9\%).

14 Con relación a presuntos responsables, llama la atención que el 66\% de los casos de asesinatos es atribuido a un grupo armado sin identificar, lo cual pone de manifiesto un nuevo modus operandi. En efecto, en algunos casos se ha podido identificar al autor material que obedece a la contratación de pandillas o combos bajo la modalidad de sicariato y se desconocen por completo las autorías intelectuales ante la carencia de judicialización por parte de los operadores de justicia (ODTPI, 2020).

15 Las regiones del país donde se concentran los asesinatos se caracterizan por la presencia de carteles del narcotráfico, una gran variedad de grupos armados como guerrillas, disidencias de las FARC, grupos paramilitares, crimen organizado. Nos encontramos así ante la reconfiguración del conflicto y la disputa del control territorial por parte de estos grupos a pesar de la firma del Acuerdo de Paz. También se registran importantes disputas económicas para el desarrollo de proyectos de hidrocarburos, minería e infraestructura. A pesar de la presencia de estos actores armados, sin embargo, la región del suroccidente colombiano se caracteriza por la presencia de 
importantes procesos organizativos de resistencia, autonomía y defensa del territorio por parte de autoridades y organizaciones indígenas.

\section{Regresividad del derecho al territorio en el marco de la pandemia}

El 25 de marzo de 2020, el gobierno adoptó un aislamiento preventivo obligatorio y decretó el estado de emergencia. Las medidas se extendieron cerca de seis meses y luego se inició una fase más flexible. Bajo este contexto se limitaron actividades de agrupamiento, locomoción y se instó a las diferentes autoridades indígenas a tomar las medidas necesarias para prevenir el contagio.

Sin embargo, este contexto ha significado una serie de desafíos para los pueblos indígenas quienes han visto un incremento de su vulnerabilidad, producto de la precariedad en materia de acceso a derechos fundamentales y de la reconfiguración del conflicto armado. De tal forma, se han identificado limitaciones en el acceso tanto a la información sobre el virus como a la infraestructura sanitaria, saneamiento básico y agua potable. A esta situación también se suman restricciones al suministro alimentario derivado de las limitaciones a la movilidad, la histórica pérdida del territorio, contaminación de fuentes hídricas y el incremento de la deforestación.

De acuerdo con el reciente informe publicado por el ODTPI sobre los derechos territoriales en el marco de la pandemia, la regresividad en el derecho al territorio de los pueblos indígenas se observa desde dos ejes. El primero está relacionado con la adopción de medidas por parte del gobierno nacional en favor del desarrollo económico $\mathrm{y}$ en detrimento de los derechos de los pueblos indígenas. El segundo eje concierne el incremento de las violaciones de derechos humanos en territorios indígenas.

El primer eje hace referencia a las decisiones tomadas por la administración Duque en aras de dinamizar la economía distando del objetivo de hacer frente a la pandemia. En el marco del confinamiento el gobierno nacional promovió una serie de medidas que afectaron directamente la garantía y goce efectivo de los derechos fundamentales de los pueblos indígenas, aumentando su vulnerabilidad en el actual contexto.

Como agravante, se destacan las siguientes actuaciones generadas desde la institucionalidad. En primer lugar, el Ministerio del Interior promovió el mecanismo de consulta previa virtual para favorecer los intereses de una gran variedad de gremios económicos; la Unidad de Restitución de Tierras expidió un acto administrativo ${ }^{3}$ para la suspensión de los términos de los procedimientos administrativos de inscripción en el Registro de Tierras Despojadas y Abandonadas Forzosamente. En segundo lugar, el gobierno nacional en cabeza del Departamento Nacional de Planeación adelantó un catastro multipropósito que tiene como finalidad la obtención de información predial para incentivar las inversiones económicas. En tercer lugar, el Ministerio de Defensa anunció la reactivación de las fumigaciones con glifosato de los cultivos de uso ilícito contradiciendo a la Corte Constitucional y exponiendo a las comunidades rurales a la hambruna al afectarse posiblemente sus cultivos de pancoger. Empero, en el caso de las comunidades indígenas, el Ministerio del Interior consideró que no era necesaria la consulta previa porque no había un traslape con comunidades indígenas. Por último, se registra el interés del gobierno de continuar con su política de militarización del territorio tras la aprobación para la instalación de una brigada militar norteamericana, 
bajo la justificación de combatir el narcotráfico en las denominadas "Zonas Futuro" ubicadas principalmente en el Pacífico nariñense, el Catatumbo, Bajo Cauca y sur de Córdoba, Arauca, Chiribiquete y Parques Nacionales Naturales aledaños (Embajada de Estados Unidos en Colombia, 2020), áreas que se traslapan con territorios de pueblos indígenas.

21 En cuanto al segundo eje relacionado con el asesinato de población indígena durante el confinamiento comprendido entre el 25 de marzo hasta el 31 de agosto de 2020, el Observatorio de la STI-CNTI ha registrado 47 asesinatos, representando el $22 \%$ del total con una tasa de crecimiento del $37 \%$ con relación al mismo periodo en el año anterior.

En consecuencia, de las medidas gubernamentales mencionadas, se han registrado combates entre grupos armados en el Chocó y Antioquia provocando el confinamiento y en otros casos, el desplazamiento forzado de comunidades emberás. En Putumayo, por otra parte, se presentaron heridos y asesinatos resultado de la política de gobierno de la erradicación forzada de cultivos de uso ilícito. También se observa una proliferación de amenazas y atentados en contra de la dirigencia del movimiento indígena por parte de grupos paramilitares y disidencias de las FARC y se presentaron atentados o asesinatos en casas de líderes indígenas aprovechando las medidas de confinamiento.

La ausencia de una implementación efectiva del Acuerdo de paz y el contexto actual de pandemia ha conllevado a un incremento de la vulnerabilidad de los pueblos indígenas. A esta situación se suman las diferentes actuaciones gubernamentales que contradicen el principio de la progresividad del derecho fundamental al territorio y a la consulta previa. Los intereses económicos y los efectos de las medidas gubernamentales se localizan en territorios caracterizados por la concentración de la tierra, la presencia de solicitudes de formalización de territorios indígenas, la reconfiguración del conflicto y el asesinato del liderazgo indígena. Esos hechos que hacen posible concluir que en Colombia están dadas las condiciones para el mantenimiento del despojo y del genocidio, situación agravada por la crisis sanitaria provocada por la COVID-19.

\section{BIBLIOGRAFÍA}

Embajada de Estados Unidos en Colombia, “Misión SFAB viene a Colombia”, 27 de mayo de 2020, https://co.usembassy.gov/es/mision-sfab-viene-a-colombia, consultado el 25 de noviembre de 2020.

Global Witness, "Defender el mañana. Crisis climática y amenazas contra las personas defensoras de la tierra y del medio ambiente", 29 de julio de 2020 https://www.globalwitness.org/es/ defending-tomorrow-es/, consultado el 25 de noviembre de 2020.

INDEPAZ, "Informe Especial: registro de líderes y personas defensoras de DDHH asesinadas desde la firma del acuerdo de paz (24/11/2016) al 15/07/2020", 15 de julio de 2020, http:// www.indepaz.org.co/wp-content/uploads/2020/07/Informe-Especial-Asesinato-lideres-socialesNov2016-Jul2020-Indepaz.pdf, consultado el 25 de noviembre de 2020. 
Observatorio de Derechos Territoriales de los Pueblos Indígenas - ODTPI , "Informe estado actual de las solicitudes de formalización de territorios indígenas 2019”, 26 de junio de 2020, https:// drive.google.com/file/d/1VPtBSXzKDrHQDXUpPQPTSQ8t6BD20Dc5/view?usp=sharing, consultado el 25 de noviembre de 2020.

ODTPI, “Informe asesinatos contra pueblos indígenas: violencia en tiempo de paz 2016 - 2019", 14 de julio de 2020, https://drive.google.com/file/d/1wDPBZMiQO_oECdgUtyn0oOnSj_8lJgm_/view, Consultado el 25 de noviembre de 2020.

ODTPI, “Sin Territorio no somos. Disputas de los territorios indígenas en contexto de pandemia, octubre de 2020, https://drive.google.com/file/d/1sVINPN7pYQ9z0jVi3novMol10aC_2iof/view, consultado el 25 de noviembre de 2020.

OXFAM, "Radiografía de la desigualdad: distribución de la tierra en Colombia", 4 de julio de 2017, https://www.oxfam.org/es/informes/radiografia-de-la-desigualdad, consultado el 25 de noviembre de 2020.

\section{NOTAS}

1. Frase de Vicente Villafañe delegado indígena por la Confederación Indígena Tayrona - CIT ante la Comisión Nacional de Territorios Indígenas - CNTI expresada en el marco de una de las sesiones de la CNTI en 2019.

2. La Guardia indígena dentro de la estructura política organizativa tiene la función social de proteger el territorio de amenazas externas o actividades que vayan en contra del derecho propio y son quienes velan por la seguridad de la comunidad a través de la realización de controles, vigilancia, recorridos, etc.

3. URT, Resolución 0307, 2020

\section{AUTOR}

\section{JULY CALDERÓN SEGURA}

Doctoranda en antropología social y etnología de la Escuela de Altos Estudios en Ciencias Sociales de París y politóloga de la Universidad del Rosario. Es coordinadora del Observatorio de Derechos Territoriales de los Pueblos Indígenas de la Secretaría Técnica Indígena de la Comisión Nacional de Tierras Indígenas (CNTI). Se ha desempeñado como asesora técnica para el fortalecimiento de organizaciones indígenas. 